\title{
EOPs: Comparación entre la eficacia de la vareniclina y la terapia de reemplazo nicotínico para la cesación tabáquica
}

\author{
Comparison between the efficacy of varenicline and nicotine replacement therapy for smoking cessation
}

Tamara Sigal *

\begin{abstract}
Resumen
A partir de la descripción del caso de un paciente fumador que recayó utilizando bupropion y desea realizar un nuevo intento, surgen las posibilidades de los parches de nicotina y de la vareniclina.

Luego de plantear la pregunta y realizar la búsqueda bibliográfica, se selecciona el único trabajo relevante para contestar la pregunta. Se revisa brevemente ciertos aspectos de la adicción al tabaco y se comenta el único ensayo aleatorizado detectado.

Este ensayo demostró que la vareniclina es más eficaz en la tasa de abstinencia al final del tratamiento que la terapia de reemplazo nicotínico (desenlace primario) aunque no muestra diferencias al año (desenlace secundario). Se concluye que hacen falta más estudios con un mejor diseño y seguimiento para permitir detectar diferencias en la tasa de abstinencia a largo plazo que comparen ambos tratamientos activos.

\section{Abstract}

After a description of the patient, a smoker that had relapsed after bupropion therapy and wishes to make a new quit attempt, the options of nicotine patches and varenicline appear. After posing the question and performing the literature search, the only relevant paper is selected.

Some aspects of smoking are reviewed, and the only article detected is summarized.

This trial showed that varenicline was more efficacious than nicotine replacement therapy at the end of treatment (primary outcome) though there were no differences at one year (secondary outcome).

It is concluded that more studies with a better design and longer follow-up are needed to be able to detect long term difference in cessation rates that compare both active strategies.
\end{abstract}

Palabras clave: vareniclina, cesación tabáquica, reemplazo nicotínico. Key words: varenicline, smoking cessation, nicotine replacement therapy.

Sigal T. Comparación entre la eficacia de la vareniclina y la terapia de reemplazo nicotínico para la cesación tabáquica. Evid. Actual. Práct. Ambul; 12(2): 7576, Abr-Jun 2009.

\section{Caso clínico}

Un médico de familia atiende un hombre de 45 años, tabaquista de 15 cigarrillos/día quien desea dejar de fumar. Él ya hizo el intento con bupropion, pero recayó, por lo que desea intentar con otra opción terapéutica. Sabe que existen una medicación relativamente nueva (Vareniclina) y los parches de nicotina.

El paciente desea saber cuál de estos métodos es más efectivo.

\section{Pregunta que generó el caso}

En pacientes tabaquistas (población) ¿el uso de vareniclina (intervención) es igualmente efectivo (resultado) que el uso de sustitutos nicotínicos (comparación)?

\section{Estrategia de búsqueda}

Se realizó una búsqueda en MEDLINE utilizando como palabras clave: "varenicline" y "nicotine", utilizando como filtro el idioma inglés.

Se detectó un único ensayo clínico controlado aleatorizado que comparaba ambas estrategias, y parecía responder adecuadamente la pregunta.

\section{Introducción}

El tabaquismo es la principal causa de muerte evitable en el mundo y responsable de cinco millones de muertes anuales, cifra que podría duplicarse en 2030 , de no mediar acciones para contrarrestar la situación. ${ }^{1}$ Los tratamientos para el abandono de tabaquismo se encuentran entre las intervenciones de prevención más costo-efectivas. ${ }^{2}$

Si bien gran parte de los fumadores desean dejar de fumar, esto no resulta tan sencillo. La recaída es frecuente y forma parte del proceso de recuperación.
Las opciones terapéuticas farmacológicas actualmente disponibles incluyen al bupropion, a la terapia de reemplazo nicotínico (parches, spray nasal, chicles) y a la vareniclina. Estudios aleatorizados doble ciego que compararon vareniclina y bupropion demostraron que la vareniclina tiene una mayor eficacia que el bupropion al final de 12 semanas de tratamiento y a los seis meses de seguimiento ${ }^{3,4}$.

Respecto de la terapia de reemplazo de nicotina (TRN) se sabe que reduce los síntomas de la abstinencia. Por ejemplo, una revisión sistemática de 90 estudios evidenció un significativo incremento en la cesación (OR=1,71; IC 95\% 1,60 a 1,83) sin diferencias significativas entre las distintas formas de administración ${ }^{5}$.

\section{Resumen de la evidencia}

Varenicline versus transdermal nicotine patch for smoking cessation: results from a randomized open-label trial. Aubin $\mathrm{H} \mathrm{y}$ col. Thorax. 2008 Aug;63(8):717-24.

\section{Objetivo}

Comparar la eficacia en la cesación tabáquica entre el uso de vareniclina durante 12 semanas versus terapia de reemplazo nicotínico durante diez semanas.

\section{Diseño, lugar y pacientes}

Ensayo abierto aleatorizado, llevado a cabo entre enero 2005 y junio 2006 en 24 centros en Bélgica, Francia, Países Bajos, Reino Unido, Estados Unidos.

Fueron incluidos participantes motivados para dejar de fumar, que habían sido reclutados en clínicas de cesación tabáquica o por avisos publicitarios locales. Fueron incluidos pacientes de 18 a 75 años, con un peso mayor a $45,5 \mathrm{~kg}$ y un índice de masa corporal (IMC) de 15 a $38 \mathrm{~kg} / \mathrm{m} 2$. Cada paciente debía fumar al menos 15 cigarrillos/día y no presentar un período de abstinencia mayor a tres meses durante el último año. Fueron excluidas las mujeres que estaban dando de mamar, las embarazadas, los pacientes con historia de cáncer o enfermedad importante 
en los últimos seis meses, depresión, dependencia al alcohol o drogas durante los 12 meses previos, alergia a la medicación, problemas dermatológicos, hipertensión (presión arterial mayor a 150/95 mmHg) insuficiencia hepática o renal, medicación habitual que tuviera interacción con la medicación utilizada en el estudio, participación en estudio previo que incluyera vareniclina o terapia de reemplazo nicotínico durante los seis meses previos.

\section{Intervención}

Se entregó a todos los pacientes un material educativo sobre cesación tabáquica y al momento del inicio del estudio, recibieron una sesión de diez minutos de consejo. Se fijó el "día D" para ambos grupos a la semana de la primera visita. El grupo asignado a vareniclina comenzó a tomar la medicación una semana antes del día $D$, mientras que los asignados a TRN comenzaron el tratamiento el "día D".

El grupo vareniclina recibió $0,5 \mathrm{mg}$ por día durante tres días, luego 0,5mg dos veces al día durante cuatro días y, por último, $1 \mathrm{mg}$ dos veces al día durante 11 semanas.

El grupo TRN recibió parches transdérmicos con $21 \mathrm{mg}$ diarios de nicotina durante seis semanas, luego $14 \mathrm{mg} /$ día por dos semanas $\mathrm{y}$, por último, $7 \mathrm{mg}$ diarios durante dos semanas.

Ambos grupos fueron seguidos telefónicamente tres días luego del "día D" y asistieron a la clínica una vez por semana.

Una vez que ambos grupos completaron el tratamiento fueron seguidos durante 40 semanas en el grupo vareniclina y durante 41 semanas en el grupo TRN, telefónica o personalmente.

\section{Medición de resultados principales}

El resultado primario fue el reporte de la tasa cesación tabáquica continua, confirmado por niveles de monóxido de carbono exhalado menores a 10 ppm durante las últimas cuatro semanas del tratamiento. El análisis fue realizado "por población que recibió al menos una dosis del tratamiento indicado".

\section{Resultados principales}

Fueron aleatorizados 757 pacientes, 378 asignados al grupo vareniclina y 379 al grupo TRN. Las pérdidas totales representaron el $34 \%$ del grupo vareniclina y el $39 \%$ del grupo TRN.

Las pérdidas reportadas durante la fase de tratamiento fueron $17,3 \%$ para el grupo vareniclina y $20,3 \%$ para el grupo TRN.

Mantuvieron la abstinencia durante las últimas cuatro semanas más pacientes del grupo vareniclina $(55,9 \%, \mathrm{n}=210)$ que del grupo TRN (43,2\%, n=160) con un OR de 1,7; IC95\% 1,26 a 2,28.

El evento adverso más frecuente fueron las nauseas (vareniclina: $37,2 \%$; TRN: $9,7 \%$ ) y no se encontraron diferencias significativas en la tasa de cesación al final del seguimiento.

\section{Conclusión de los autores}

En este estudio abierto, la vareniclina demostró ser segura y los pacientes en grupo vareniclina tuvieron una mayor tasa de cesación tabáquica que los asignados a parches de nicotina. EI OR de abstinencia de vareniclina sobre TRN al final del tratamiento $(O R=1,7)$ fue similar al reportado semanas después del cese tabáquico, aproximándose también al de un estudio doble ciego que comparó vareniclina y bupropion, con un OR de 1,9 al final del tratamiento.

\section{Comentario}

La vareniclina logró una mejor tasa de cesación tabáquica al final del tratamiento que la TRN. Sin embargo el estudio no encontró diferencias significativas en el seguimiento a largo plazo (tal vez por falta de poder) resultado que era considerado como desenlace secundario y que tiene una importancia enorme. Clínicamente, sería importante conocer la tasa de abstinencia a largo plazo y estar seguro de que esta mejora al final del tratamiento se traslade a una mejora sostenida en el tiempo.

Como el análisis fue realizado de acuerdo al grupo asignado en la aleatorización y a haber recibido al menos una dosis (análisis pre-especificado) estos resultados podían entonces subestimar la eficacia de la vareniclina en comparación a la TRN debido a que un $2 \%(n=9)$ de los pacientes del grupo TRN salieron del estudio antes de recibir el tratamiento en comparación con el $0,5 \%(n=2)$ que lo hizo del grupo vareniclina.

En contraposición al análisis "por intención de tratar", el análisis "de acuerdo a la población que recibió la primera dosis de tratamiento" (por protocolo) implica sesgos y posibilidad de entrecruzamiento entre las poblaciones. Con esta forma de análisis no se conservan las ventajas de la aleatorización, como sí ocurre en el análisis por intención de tratar. Éste último se aproxima más a la práctica cotidiana, dado que muchos pacientes no cumplen con el tratamiento prescripto. Además, el análisis por protocolo disminuye el tamaño muestral (tal como ocurrió en este estudio) lo que implica disminución del poder del estudio.

Los diseños abiertos tienen algunas limitaciones. Por ejemplo, si la gente le tiene más confianza al tratamiento nuevo oral, eso puede influir en una mayor tasa de cesación. Por ejemplo, la diferencia en la tasa de abandono del estudio luego de la asignación y antes de la primera dosis pudo estar influenciada por sesgos de motivación.

Otra limitación del estudio es no haber incluido adolescentes, fumadores comprometidos clínicamente (p. ej. enfermedad cardiaca activa) pacientes con trastornos psiquiátricos, ni pacientes no caucásicos.

Tratando de llevar estos resultados a la práctica, consideramos que es bueno decidir junto al paciente qué terapéutica utilizar para la cesación tabáquica, dado que las motivaciones y preferencias de los pacientes están fuertemente relacionadas con los resultados. Se debe, además, tener en cuenta la posibilidad de recaídas y explicarle al paciente que éstas son esperables con cualquier tratamiento, siendo parte de la recuperación y que cuantos más intentos de cesación existan, hay más probabilidades de abandono definitivo.

\section{Conclusión}

Un único ensayo clínico detectado demostró que la vareniclina es más eficaz a corto plazo en la tasa de abstinencia al final del tratamiento que la terapia de reemplazo nicotínico. Sin embargo hacen falta más estudios con diseño doble ciego, que incluyan más sujetos, que sean analizados por intención de tratar y que evalúen resultados a más largo plazo.

Referencias

1. Ministro de Salud y Ambiente de la Nación y Entidades Académicas, Científicas e Instituciones representativas del control del tabaco en Argentina. Resumen de la GUÍA NACIONAL DE TRATAMIENTO DE LA ADICCIÓN AL TABACO.

2. Fiore M. Treating tobacco use and dependence: an introduction to the US Public Health Service Clinical Practice Guidelines. Respir Care 2000;45:1196-9.

3. Gonzales D y col. Varenicline, an alpha4beta2 nicotinic acetylcholine receptor partial agonist, vs sustained-release bupropion and placebo for smoking cessation: a randomized controlled trial. JAMA 2006;296:47-55.

4. Jorenby $D$ y col. Efficacy of varenicline, an alpha4beta2 nicotinic acetylcholine receptor partial agonist, vs placebo or sustained-release bupropion for smoking cessation: a randomized controlled trial. JAMA 2006;296:56-63.

5. Lancaster T y col. For the Cochrane Tobacco Addiction Review group.Effectiveness of interventions to help people stop smoking: findings from the Cochrane Library. BMJ. 2000 Aug 5;321(7257):355-8. 